\title{
Controlar para educar? O poder como forma de construção de sujeitos na perspectiva dicotômica dominante-dominado
}

\begin{abstract}
RESUMO: Este estudo refere-se à análise da sujeição presente historicamente na educação. Propõe refletir sobre o papel da educação associada às diferentes concepções de poder, a relação deste com o saber, com a construção do sujeito e sua instituição no sistema educacional. Um dos aspectos a discutir será a relação estabelecida entre o ato educativo e o controle, o qual determina comportamentos e atitudes de educandos e educadores. Deseja-se questionar modelos tidos como naturais que apesar da "modernização" continuam formando sujeitos dóceis e disciplinados.
\end{abstract}

PALAVRAS CHAVES: Poder e Educação. Relação saber-poder. Controle. Comportamento do educando. Comportamento do professor.

\section{Introdução}

A vida humana, tal qual conhecemos e concebemos, encontrase enredada num contexto repleto de poder e, por consequência, tecida pelas malhas do controle. Desta forma, não há como dissolver a relação estabelecida entre os seres humanos, pautada no poder e resguardada pelo controle. A história nos relata os diferentes meios pelos quais o poder e seu vigoroso instrumento de consolidação, o controle, tem se expressado de forma diferenciada. Estruturam-se verdadeiros paradigmas, permitindo, assim, uma análise histórico-social do fenômeno, sem buscar aprofundamentos maiores nos campos da psicologia, da antropologia ou da mística. Isto, para ilustrar a complexidade e a mobilidade do tema.

Há que se dizer, entretanto, que não há qualquer ação humana que não demande poder, ao contrário, este é um dos fundamentos do fazer e do devir humano. Assumir uma postura política é manifestar uma opção que, em última instância, é determinada pela definição do papel do poder num determinado contexto. Autores, como Foucault, tratam do poder como algo expressamente presente em tudo o que diz respeito ao humano.

Por se tratar de uma ação humana, a educação não está imune às ações do poder expressas pelo controle. Ao contrário, poderá servir ao poder e ao controle, de tal forma, que servirá como

\section{Nilton Bruno Tomelin}

Professor do Centro Universitário de Brusque UNIFEBE

\section{Rosane Nardi Melz}

Especialista Formação Pedagógica e Gestão da Educação, Professora de Educação Básica 
instrumento de sua consolidação. Isso significa que a educação deve manter-se distante da cômoda atitude de inércia ou da covarde postura de submissão. A educação não pode ser refém e/ ou algoz de seres humanos aprisionados pelos perversos laços do poder ou pelo potencial desumanizador do controle.

A história da educação denuncia constantemente a relação entre o conhecimento e o poder, no que se refere à escola, transformando-a em ente normatizador deste fenômeno. A normatização imprime um caráter de aceitabilidade, seja por ignorância ou imposição de situações inaceitáveis em condições comuns. Em nome disso, gerações têm sido rechaçadas em detrimento de interesses que parecem circunstancialmente velados, muitas vezes perversos, desumanos e imorais. É em nome destas gerações que, segundo D'Ambrósio (1999, p. 14), "[...] é importante lembrar que a ação do professor e dos sistemas educacionais em geral mostrará seus efeitos somente no futuro. Um futuro que ninguém conhece. Um futuro no qual estarão agindo as crianças que hoje confia a nós, os educadores". Trata-se de uma opção por valores e princípios e não de interesses. Isso sem considerar a inobservância de princípios éticos que, apesar de amplas discussões, costumam não se inserir num processo de construção humana tanto quanto deveriam estar.

A ausência de princípios humanos e a necessidade de conquistas fizeram do poder uma das grandes metas a alcançar, independentemente do meio. Assim, questões como intolerância religiosa e étnica, guerras civis não declaradas, progresso exclusivo, questões sociais mal resolvidas, recursos tecnológicos disponíveis a poucos são temas que não se discutem na escola, como também determinam sua formatação. Historicamente, nos deparamos com inúmeros dilemas a respeito da escola como instituição pública que ainda não determinou o verdadeiro grau de sua publicidade, uma vez que nos deparamos, diuturnamente, com índices de exclusão, evasão, repetência e formação absolutamente desqualificada, sob os mais variados aspectos.

A relação da escola com o poder é algo temível, pois em determinadas situações a própria escola, quando não é genitora, é disseminadora destas mazelas em nome da sua relação com parte da sociedade. Tal relação atinge os horrendos extremos da medíocre submissão, em face da necessidade aparente que tem de se adequar ao que deseja tal fragmento social. Mas de que parte

34 R. Faced, Salvador, n.13, p.33-44, jan./jun. 2008 
se faz referência? A parte que conquista o poder, seja pela via (pseudo) democrática ou seja por outras que utilizam a educação, como instrumento de consolidação de ideologias. A escola, então, assume uma postura de submissão e subserviência, demonstrando que ainda não se atingiu um patamar de maturidade ética-institucional e solidária-humana capaz de fazer da educação um campo de redenção do ser humano, enquanto sujeito capaz de sua própria (trans)formação.

\section{O poder como fenômeno social}

Numa discussão de relativa profundidade, surgem questionamentos que traduzem o cotidiano social e histórico em que se insere a instituição escolar. Analisando comportamentos sustentados pelo senso comum, percebe-se que a escola é acusada por uns de reprimir e por outros por ser liberal demais; para alguns, cumpre sua função social e para outros não alcança os patamares mínimos de eficácia, eficiência e efetividade. Como derivação desta dicotômica realidade, a instituição escolar afirma seu interesse de autorrehumanização quando aponta como necessário um estudo do homem como ser histórico, biológico, psíquico, social e transcendente. Assumindo que tende a escola a ultrapassar os limites da docência tradicional derivada do Liceu, de Aristóteles.

Desta maneira, ainda se conservam as discussões meramente no maniqueísmo (repressão x liberalismo), o que se deve à falta de uma identidade teórica, metodológica e conceitual. Isto faz com que ocorra uma migração de poderes sobre a educação, subordinando-a a tudo e a todos. Tornou-se a instituição escolar, corresponsável pelos sucessos e fracassos da sociedade como um todo. Disto decorre um perigo avassalador: pode-se estar imergindo num modelo de submissão ao poder de práticas e conceitos criados por ela e que se disseminam pela sociedade, através de poderosos mecanismos de controle. Assim, por exemplo, uma instituição escolar eleva seu conceito de acordo com o número de aprovados em vestibulares entre seus egressos.

Costuma-se dizer que a educação tem, a princípio, por finalidade operacionalizar mudanças que promovam o desenvolvimento do homem e da sociedade. Para tanto, necessita-se que atinja a coletividade nos mais diferentes níveis, buscando ampliar os ho- 
rizontes pessoais, inserindo o sujeito no contexto social e viceversa. A prática da democracia solidária é um exercício capaz de compreender este caráter. Através dela se percebe o grande risco das generalizações e relativizações instituídas mediante o uso clássico de práticas seletivas (ideológicas e pessoais), em que a opção de uma maioria (por vezes enganada e alienada) se sobrepõe à lucidez de uma minoria.

Analisando historicamente, nota-se o poder que a mídia, por exemplo, exerce sobre uma grande maioria alienada, o que tem feito uma minoria pensante, reflexiva e ativa, ser ignorada. Esta realidade tem permitido identificar poderes e controles absolutos, sem utilizar de força física, ameaças e retaliações. A submissão se dá de forma muito mais subliminar e sutil, porém, não menos traumática e ostensiva. Neste contexto, a educação também sofre uma espécie de modelação (formatação), no sentido de ratificar esta prática considerando-a até mesmo natural e necessária.

Para dar sustentação ao poder e legitimar o controle sem a utilização da força física, é preciso instrumentalizar os agentes detentores do poder com algo tão poderoso quanto a força: o conhecimento. Pode-se dizer que o conhecimento é o pensamento que resulta da relação do sujeito que conhece e do objeto a ser conhecido. É nessa associação que o saber é produzido e acumulado pelo homem ao longo de sua existência. Saber passa a ser economicamente interessante.

O que se percebe, entretanto, é que no ritmo em que a humanidade produz conhecimento, especialmente ao longo do século XX e início do século XXI, torna-se praticamente impossível deter saber que se sustente válido por algum tempo significativo. Até então, os que detinham a chamada "base sólida do saber" teriam as condições elementares para dominar os demais. Segundo Meis (2002, p. 71-72),

[...] uma das principais características dessa educação era a sua imutabilidade. Os conhecimentos adquiridos na mocidade permaneciam válidos ao longo de toda a sua vida, uma vez que, até o início do século $\mathrm{XX}$, o crescimento do saber era muito lento e, em paralelo a ele, a variação dos costumes sociais estabelecidos era também bem lenta.

Desta forma, deter poder pela contenção de saberes já não é uma garantia como era outrora. Ao contrário, a deterioração do 
saber, aparentemente, obriga a aceitar sua condição de interminável ou associa-se a formas de poder que garantam determinado status de autosustentabilidade.

Mas, o inverso é cruelmente verdadeiro. Quem não detém saber (sistematizado) algum, não exerce qualquer poder, mas ao contrário, sofrerá todas as privações e violências que emanam da relação entre opressor e oprimido. De acordo com Foucault (1977, p. 35), "Nos "excessos" dos suplícios, se investe toda a economia do poder". Assim, o suplício do não saber não se restringe ao fato de ignorar, mas as implicações que isto representa para quem não sabe. Quem não sabe é sumariamente excluído(a) da condição essencialmente humana.

Vale lembrar também que muito do conhecimento acumulado pela humanidade pauta-se em equívocos, dogmas e axiomas. Tais elementos podem distorcer a concepção que se possa construir de ciência através de verdades absolutas. Graças à experiência histórica vivida, concebe-se de forma sensível a ideia de que estamos numa (re)construção permanente do saber. Para Foucault (2000, p. 110),

O saber não é uma soma de conhecimentos - pois destes sempre se deve poder dizer se são verdadeiros ou falsos, exatos ou não, aproximativos ou definidos, contraditórios ou coerentes; nenhuma dessas distinções é pertinente para descrever o saber, que é o conjunto dos elementos (objetos, tipos de formulações, conceitos e escolhas teóricas) formados a partir de uma só e mesma positividade, no campo de uma formação discursiva unitária.

A sensibilidade, que não é a mera consciência dos fatos, nos permite elaborar um conhecimento mais flexível, menos dominador e mais libertador. Cientificidade e liberdade parecem dividir o mesmo palco no ato de (re)conceituar o poder do ato educativo sobre as pessoas. Não se pode omitir, no entanto, a capacidade que a ciência tem de intervir na vida das pessoas, porém, uma educação sensível à não neutralidade da ciência, será capaz de transformar esta intervenção numa ação edificadora de uma formação ética, solidária e humana.

Tal educação não poderá ser exclusiva e taxonômica. Desta maneira, há que se pensar na face obscura do acesso limitado, que ronda o conhecimento e, por conseguinte, sua efetiva aplica- 
ção em favor da maioria ou da totalidade das pessoas. Se, por um lado, existe uma necessidade histórica de se promover um conhecimento liberto dos grilhões do poder maçante, por outro, o poder se manifesta através da sua exclusividade. Se o conhecimento deriva de interações sociohistóricas há que se pensar e agir para incluir o máximo de pessoas neste processo. A limitação a acessibilidades é a manifestação mais cruel do poder de controle social que se conhece hoje. Seres humanos são estratificados considerando os mais diversos critérios: etnia, sexo, classe social, poder econômico, etc.

A estratificação compartimentaliza diferentes categorias de seres humanos, tendo cada qual uma função definida. Dessa forma, tendo como meio a educação, os sujeitos podem ser produzidos como objetos do conhecimento, tanto estando preparados para serem dominados, quanto para dominar. Esta postura de dominante e dominado é cômoda e torna o sujeito, seu dependente. Renunciar a ela, ou desfazer-se dela, requer coragem e determinação suficientes para sacrificar-se...

Um novo homem e uma nova mulher se evidenciam neste novo contexto. Reconhecidamente, o conhecimento é percebido de forma não neutra, tomado por valores que transcendem os limites de métodos sistematizadores. As relações estabelecidas entre conhecimento e poder não são apenas linhas e elos de contato, mas valores que permeiam, penetram e interagem com ambos. Esta forma de relação faz com que o conhecimento seja constantemente (trans)formado e o poder concebido das mais variadas formas. Graças a isso, há uma constante alteração da própria relação estabelecida e do exercício do poder.

Sabe-se que para alcançar este nível de convívio entre homem, conhecimento e poder, faz-se necessária uma permanente flexibilização entre eles, permeada por valores éticos e solidários. O que se tem percebido é que o ser humano constitui a si e ao outro numa relação de duplo sentido: dominante e dominado, poder e saber. Este maniqueísmo parece ter se naturalizado, representando um desafio de alta complexidade, sobre a qual não nos debruçaremos por ora. O fato é que não podemos refletir sobre a liberdade sem antes fazer com que os cativos percebam que ela é possível. Desmistificar a máxima do "antes pouco que nada" será algo a ser construído de forma gradual. Contentar-se com as migalhas das mesas fartas tem sido a condição primordial 
de sobrevivência e mantida por moralismos consolidados na relação dominante x dominado.

O poder pelo poder não representa outra coisa, senão apenas poder acumulado. Mas as relações construídas a partir dele impõe uma efetiva (trans)formação de paradigmas, o que tem feito de cada sujeito uma célula dependente de outra construindo o que chamamos de tecido social, que no modelo humano significa uma total dependência intraespecífica. Nesta perspectiva, surge um novo ator do processo: a autoridade.

\section{A autoridade guardiã e refém de sua prática na perspectiva da dicotomia dominante-dominado}

Uma organização social, familiar ou um outro grupo qualquer, necessita de certa organização determinada pela sistematização de forma hierárquica peculiar. Nela se estabelecem funções, atribuições, obrigações, direitos e deveres universais que preservam características e determinam mudanças no referido grupo. Uma das responsáveis por isto é a autoridade, determinada e associada ao poder. É ela quem toma para si a responsabilidade de guarnecer o poder e perpetuá-lo, através de práticas diversas dentre as quais o controle.

Não nos ateremos a detalhar o processo de evolução que conduz historicamente a compreender os diferentes perfis de autoridade. Apenas valeremo-nos de alguns destes perfis, para que possamos compreender que o poder e o próprio controle não são, por si, sinônimo de dominação, exclusão e repressão.

O que se tem percebido nos tempos atuais é uma despersonalização da autoridade. Prova disso é que ditadores são cada vez mais raros e monarquias têm perdido sistematicamente o poder onde ainda persistem. A autoridade agora é impessoal, ideológica e institucional. Assim, por exemplo, a sociedade moderna tem na comunicação uma das formas de poder mais evidente, pois determina normas disciplinares (comportamentais, de consumo) que são capazes de manter a coesão de um grupo social, influenciando, assim, atitudes e opiniões. Trata-se de um discurso ideologicamente autoritário e de grande influência.

Os sistemas de comunicação cuidam para que sua autoridade não se perca e ao mesmo tempo não saberiam sobreviver sem ela. Desse modo, a autoridade possui duplo sentido: o de guardiã 
e de refém. Uma outra diferença que se percebe é a forma como a nova autoridade se expressa. Ao longo de muitos anos, a autoridade utilizou-se da força física, violência e humilhação pública para se estabelecer. Agora, a autoridade utiliza-se da persuasão, do acordo e da negociação para se estabelecer. Porém, é identificado também um rol de outros meios menos ortodoxos em que a autoridade se estabelece: imposição pela punição prévia, repressão moral, chantagem, entre outros. Em todas as formas de expressão da autoridade percebe-se uma presença inconteste do poder. Seja pela punição física, pela negociação ou pela repressão velada, o poder há que se manifestar sempre. O que se diferencia é a maneira pela qual o poder é utilizado. Esta diferenciação é determinada pelos valores que permeiam a relação entre homem, saber e poder.

Nas instituições de ensino, o apelo é mais institucional: a disciplina. Disciplinado, o sistema educacional utiliza-se de práticas fundadas na vigilância constante que classifica, registra, através de boletins de avaliação, o sucesso ou insucesso do educando. Não há uma pessoa, uma ideologia, mas instituições (escola, família) que tornam o exercício do poder uma prática legítima, temida e sustentável. Sem contar que futuras seleções (vestibulares, concursos) utilizam-se dos eventuais resultados obtidos do crivo escolar. Não podemos imaginar que isto seja involuntário ou fruto de uma submissão ingênua. Segundo Guareschi (1999, p. 99), "[...] quando essa escola não executar a política e os interesses do grupo no poder, ela é censurada, mudada, reformada, e até mesmo fechada". Novamente se pode dizer que a expressão do poder e da autoridade não se dá por meio de negociações, mas pela potencialidade de expressar a dominação e imposição de métodos convencionados.

Há também a autoridade semissubliminar que determina economicamente quem pode (domina) e quem obedece (dominado). Os excluídos e analfabetos (funcionais e digitais), por exemplo, passam, então, a encampar um lamentável exército de sujeitos de segunda classe, objetos de frequentes pesquisas que, por sua vez, os incluem no que se pode chamar de 'fenômeno natural' da 'modernidade'. Esta é outra face do poder e do controle. Poder que determinada quem pertence a cada estrato social ou cultural e controle para saber quem são e o que faz cada sujeito em cada categoria. A educação exerce papel preponderante na função de 
'naturalizar' a exclusão e a diferenciação de seres humanos, sendo muitas vezes a primeira seletora. Anualmente, sonhos e desejos são sepultados em nome da qualidade exigida pelo mercado que, por sua vez, expressa a autoridade e o poder de quem domina econômica e politicamente o contexto social.

Este é um quadro que efetivamente está sendo revisto, pois, além de se buscar uma ocultação maior dos horrores do passado, há correntes no meio educacional, que buscam novas formas de exercer o poder. Assim, supostamente mais humanos, suavizamos os limites para que educandos, educadores e educadoras tenham uma relação mais amistosa, chegando até a afetividade (aparente). Esquecemos, porém, que esta "evolução" nos ligou a outras amarras, mais brandas, sutis. Porém, tal sutileza desaparece quando imaginamos que até mesmo uma refeição é negada a uma grande parcela da população mundial.

A sujeição, do educador e da educadora, ao sistema indica a escola como espaço contraditório, uma vez que, como anteriormente citado, tem por finalidade operacionalizar mudanças que possibilitem o desenvolvimento do homem. O educador e a educadora ao aceitarem a sua condição de reprodução das relações de poder (dominado) não ensinam a questionar o próprio sistema (dominante). Um discurso camuflado sob forma de educação. Uma educação que retoma o primórdio conceito de pedagogo (sujeito que conduz) que nada pode fazer, senão reproduzir e repassar o que the disseram. Fazer educação torna-se uma espécie de exercício de formatação, adaptação, enquadramento, a exemplo do Liceu de Aristóteles, conforme já citamos.

Entretanto, ao se compreender a educação como sujeição, torna-se possível justificar e lamentar que esta já não cumpra seu papel, devendo ser repensada e reinventada. O questionamento de antigos paradoxos, como a neutralidade da escola e do conhecimento escolar, e a definição de currículos e métodos de ensino e sua forma de avaliação são apenas alguns critérios a serem repensados. Trata-se de estabelecer uma ampla redimensão de valores e princípios que norteiam a função social, política, humana, filosófica, ética e planetária da Terra. Isto é que podemos chamar de 'escola que queremos'.

Mas, a escola que temos ainda está longe da que queremos. Certamente nunca se poderá expressar a equação real = ideal. Torna-se necessário perceber, então, que esta grande máquina de 
disciplinar (escola) tem grande utilidade econômica e política, uma vez que colabora na produção de sujeitos autogovernados (filas, carteiras, turmas, salas, espaços,...) onde aprendem desde cedo seus limites, controlando e vigiando reciprocamente uns aos outros. Mais grave do que isso, não saberiam o que fazer se não houvesse mais filas, carteiras, turmas, salas, espaços. Atingese, assim, o ápice da negação humana: o oprimido não consegue sobreviver sem o jugo do opressor. Assim, em Freire (1999, p. 30), "[...] a desumanização que não se verifica apenas nos que têm sua humanidade roubada, mas também, ainda que de forma diferente, nos que a roubam, é distorção da vocação do ser mais". Por isso, há por parte do dominante, um pseudo ser mais, que se transforma numa vontade coletiva e direcionada à universalidade, impondo poder que se consolida por meios pouco ortodoxos de controle. Estabelece-se, então, um poderoso contexto de autoritarismo.

Uma educação libertária deverá se preocupar em formar gerações capazes de se autodirecionar ou a optar por autoridades ideológicas e institucionais que lhe sejam benéficas. Se precisamos de educadores e educadoras menos autoritários, então precisamos fazer com que as crianças creditem sua ação disciplinada a outra entidade e com outro perfil. Que seja uma disciplina pautada no respeito, na tolerância e na convivência e que seja flexível o suficiente para promover o bem comum. Uma autoridade ética, sem vítimas e sem algozes.

Trata-se de uma autoridade legitimada pela diferença que sua presença representa na vida das pessoas. Conforme Freire (1999, p. 104), "[...] a autoridade coerentemente democrática está convicta de que a disciplina verdadeira não existe na estagnação, no silêncio, mas no alvoroço dos inquietos, na dúvida que instiga, na esperança que desperta". A disciplina então é determinada pela determinação de prioridades de interesse e impacto coletivo.

Um novo conceito de autoridade, uma nova concepção de poder e novos instrumentos para legitimá-lo. A complexidade do tema exige longas discussões e reflexões que nos impõem perceber as frequentes ilusões de que somos vítimas e das possibilidades que ainda temos. 


\section{Conclusões: o poder e a perspectiva dicotômica dominante-dominado no contexto escolar}

A complexidade da discussão nos limita a admitir que o tema está repleto de ilusões e incompreensões. Se o educador e a educadora se veem poderosos (dominantes) diante de seus educandos (dominados) então, são tão submissos quanto estes quando se submetem ao que chamamos de sistema. Este, por sua vez, se encolhe diante dos interesses que o financiam. O fato é que o poder instiga a imaginação e ambição de muitos e, ao que parece, a combinação destes dois itens resulta em grande ilusão.

Educar torna-se uma espécie de adestramento em que após um período de vigilância, os que se submetem a menos punições para compreender a ordem das coisas são aprovados e recomendados. Os outros planos políticos pedagógicos (PPP) chamam de alunos críticos e cidadãos, ao contrário do que está no papel, tendem a aprovações restritas, reprovações ou, em muitos casos, são convidados a se retirar. Costuma-se dizer que a escola da vida os ensinará.

As proposições que temos são simples: desvelar a verdadeira face da autoridade sobre o educador e a educadora, para que sejam mais honestos consigo e com seus educandos; pautar o ato educativo em valores que não necessitem do rigor absoluto do controle para que sejam respeitados; identificar a escola, como espaço de maturação humana, exercício da cidadania, da democracia, da solidariedade e da ética.

Control to educate? The power as form of construction of citizens in the perspective of the dominant-dominated relation

ABSTRACT:This study refers to the analysis of the subjection historically present on education. Its goal is to think on education's role associate to different conceptions of power, its relation with knowledge, with customer's construction and its institution on the educational system. One of the aspects to be discussed will be the established relation between the educative act and the control, what determines behaviors and attitudes from the one who educates and the one who is educated. It's our will to question the examples given as natural or common because, besides modernization, have been building up kind and disciplined customers.

KEY WORDS: Power and education. Relationship between knowing and power. Control. Student's behave. Teacher's behave. 


\section{Referências}

D'AMBRÓSIO, Ubiratan. Educação para uma sociedade em transição. Campinas, SP: Papirus, 1999.

FOUCAULT, Michel. Arqueologia das ciências e história dos sistemas de pensamento. Rio de Janeiro: Forense Universitária, 2000. (Ditos \& escritos, 2).

Vigiar e punir: nascimento da prisão. Petrópolis: Vozes, 1977.

FREIRE, Paulo. Pedagogia da autonomia: saberes necessários à prática educativa. 15. ed. São Paulo: Paz e Terra, 1999. (Leitura).

GUARESCHI, Pedrinho. Sociologia crítica: alternativas de mudança. 46. ed. Porto Alegre: EDIPUCRS, 1999.

MEIS, Leopoldo de. Ciência, educação e o conflito humanotecnológico. 2. ed. São Paulo: Senac, 2002. 